\title{
Psychometric Properties of Belief into Action Scale among University Students in China
}

\author{
Zhizhong Wang, Ph.D., ${ }^{1}$ Hui Ma, M.D., ${ }^{2}$ Ye Rong, Ph.D., ${ }^{3}$ Harold G. Koenig, M. D. ${ }^{2,4} 5$ \\ ${ }^{1}$ Associate Professor, Department of Epidemiology and Statistics, School of Public Health, Ningxia Medical University, \\ Yinchuan, Ningxia, China. \\ ${ }^{2}$ Department of Epidemiology and Statistics, School of Public Health, Ningxia Medical University, Yinchuan, Ningxia, \\ China. \\ ${ }^{3}$ Brain \& Mind Research Institute, Sydney University, Sydney, Australia. \\ ${ }^{4}$ Professor of Psychiatry \& Behavioral Sciences, Associate Professor of Medicine, Duke University Medical Center, \\ Durham, North Carolina, USA. \\ ${ }^{5}$ Department of Medicine, Adjunct Professor, King Abdulaziz University, Jeddah, Saudi Arabia. \\ Correspondence: Zhi Zhong Wang, Ph.D., Associate Professor, Department of Epidemiology and Statistics, School of \\ Public Health, Ningxia Medical University, Yinchuan, Ningxia, China. \\ Funding support: Ningxia Medical University Students Scientific Funding (2015). The authors have no conflicts of \\ interest. \\ Received: February 11, 2016 \\ Accepted: February 25, 2016 \\ Available online: February 26, 2016 \\ doi:10.11114/ijsss.v4i3.1363 \\ URL: http://dx.doi.org/10.11114/ijsss.v4i3.1363
}

\begin{abstract}
Objectives: We examine the reliability and validity of the Belief into Action (BIAC) scale among university students in provinces across Mainland China.

Method: The BIAC scale and Religious Commitment Inventory-10 were translated into Chinese, and administered with several other psychosocial measures to 1,830 college students from three universities in China. To assess test-retest reliability, the BIAC scale was re-administered after two weeks to 133 college students.

Results: Three factors were extracted using principal components analysis with Promax rotation, which explained 66.3\% of the variance in the BIAC. Confirmative factor analysis verified the three factor model $\left(\chi^{2}=232.03 ; \mathrm{df}=31 ; p<0.001\right.$, $\mathrm{CFI}=0.95$ ). Cronbach's alpha for the BIAC scale was 0.83, and test-retest ICCs ranged from 0.41 to 0.90. The BIAC scale total score and the RCI-10 subscales were significantly correlated $(r=0.60-0.67, \mathrm{p}<0.001)$.
\end{abstract}

Conclusion: The BIAC scale is a reliable and valid measure of religiosity in Chinese college students.

Keywords: religion, religiosity, belief into action scale, measurement

\section{Introduction}

\subsection{Background}

China is a vast country with over 1.3 billion people whose religious beliefs vary from Buddhism to Daoism to Confucianism to Western religions to no religion (Fan, 2003). Those without a religious affiliation far outnumber those who have one, given the Chinese government's policy toward religious involvement in the past (Yang, 2010). This, however, is changing as religious freedom has been rapidly spreading throughout China as the government has taken a much less restrictive attitude and has begun to support social reforms as its economic growth has expanded (Stark, 2011). As more and more Chinese have experienced the new freedom of religious worship and have become willing to admit having religious beliefs, the possibility of studying religion's effects on mental, social, and physical health has become a real possibility, as it has for the past three decades in the West (Bonelli \& Koenig, 2013; Koenig, 2012).

\subsection{Importance}

Research on religion and health, of course, requires measures to assess religiosity in a non-Christian, non-Western country such as China, and researchers have emphasized the need for better measures that are sensitive to the wide 
range of beliefs, practices, and cultures in such regions of the world (Krauss, Hamzah, \& Idris, 2007; Traphagan, 2005). There are concerns, however, that existing measures may not be sensitive enough to assess religiosity in countries where the prevalence of religious beliefs and practices are very low or very high (Koenig, 2008). Although the majority of the Chinese population is not religious, there are certain sections of the country (particularly western China) where Muslims make up close to one-third of the population, and these individuals are often very religious (Chuah, 2004). Thus, there is need for a measure of religiosity that is sensitive enough to capture a wide range of religious beliefs and practices.

\subsection{Specific Aims}

The purpose of the present study, then, is to examine the psychometric properties of the BIAC in Mainland China, an area of the world known for low levels of religiosity, and therefore to determine its reliability, validity, and ability to discriminate the religious from the non-religious in a population of college students chosen from all over the country.

\section{Methods}

\subsection{Participants}

College students from three universities in China were recruited into the study: (1) Ningxia Medical University (NXMU) located in Ningxia province, an underdeveloped area in Western China; (2) Southern Medical University (SMU) located in Guangdong province, a well-developed area of Eastern China; and (3) Shaanxi University of Chinese Medicine (SUCM) located in Shaanxi province, a moderate developed area in Mid-western China (Figure 1).

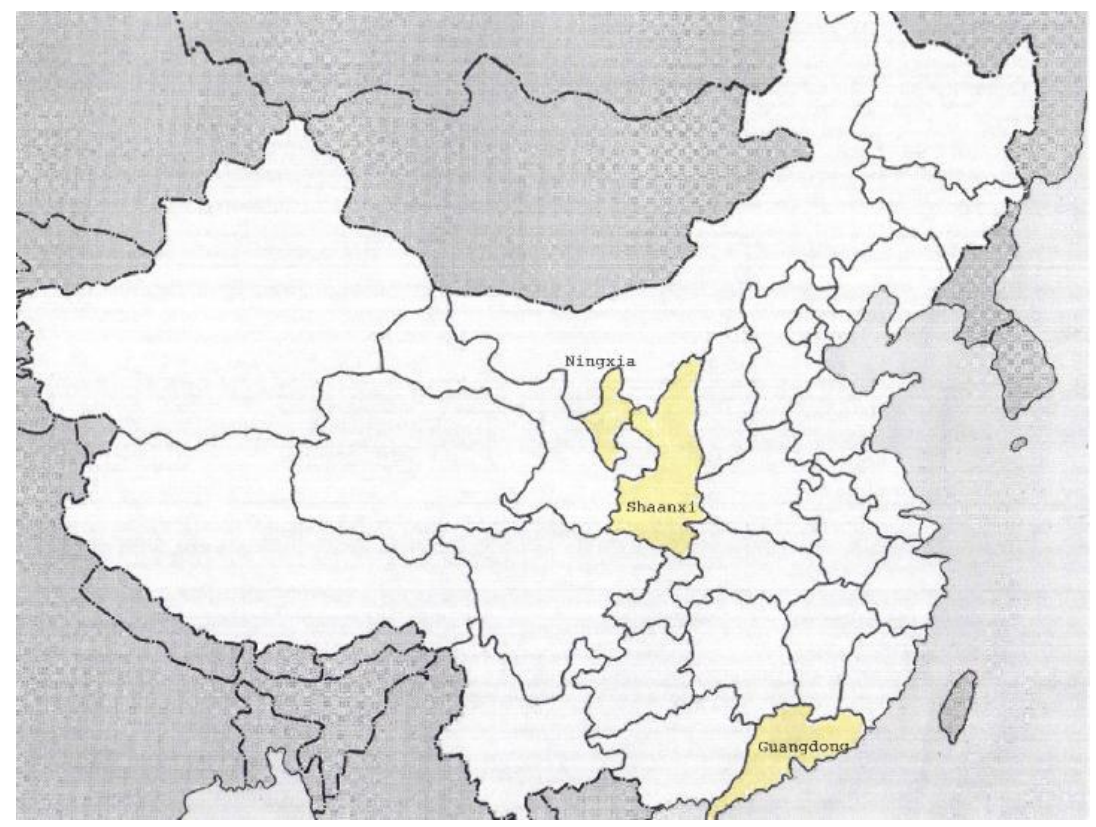

Figure 1. Map of China with provinces highlighted where survey administered

\subsection{Sampling Procedure}

A cluster sampling method (Sampford, 1962) was used to select university students. Students registered in the same class were defined as a cluster (usually 35-45 students). Twenty-five classes at NXMU were selected depending on if they were free during the time of the survey $(n=1078)$; eight classes were selected at SMU $(n=415)$; and eight classes were selected at SUCM ( $\mathrm{n}=408$. Of the 1902 students that received the survey, 1861 (97.8\%) returned it (1059 from NXMU, 401 from SMU, and 401 from SUCM)of the 1861 participants, 31 students did not complete at least $70 \%$ of the BIA scale, resulting in a final sample size of 1830 for analysis.

\subsection{Participant Characteristics}

Table 1 describes the characteristics of the 1830 participants (average age 21.5 years with SD 1.3). The majority of participants were female (68.7\%). Religious affiliations were 13.8\% Buddhist or Taoists, $18.0 \%$ Muslim, 1.6\% Western religious groups, and $66.6 \%$ no affiliation. With regard to ethnicity, $19.9 \%$ were minorities. Demographic characteristics, scale scores, and participants' religious characteristics are presented in Table 1. Compared to males, females were younger, the education of their parents was higher $(\mathrm{p}<0.05)$, and somewhat surprisingly, reported lower social interaction scores $(\mathrm{p}<0.001)$. 
Table 1. Characteristics of the sample

\begin{tabular}{|c|c|c|c|}
\hline & $\begin{array}{c}\text { Overall } \\
(\mathrm{n}=1,830)\end{array}$ & $\begin{array}{c}\text { Male } \\
(n=573)\end{array}$ & $\begin{array}{c}\text { Female } \\
(n=1,257)\end{array}$ \\
\hline \multicolumn{4}{|l|}{ Demographics } \\
\hline Age, y, mean (SD) & $21.5(1.3)$ & $21.7(1.4)$ & $21.4(1.3)^{* * *}$ \\
\hline Education of parents, $\mathrm{y}$, mean (SD) & $9.8(4.0)$ & $9.5(4.1)$ & $10.0(3.9)^{*}$ \\
\hline Ethnicity, Minority, \% (n) & $19.9(364)$ & $21.3(122)$ & $19.2(242)$ \\
\hline Urban/rural, rural, \% (n) & $66.1(1,199)$ & $68.8(389)$ & $64.8(810)$ \\
\hline \multicolumn{4}{|l|}{ University, \% (n) } \\
\hline Ningxia Medical University & $56.6(1,036)$ & $59.5(341)$ & $55.3(695)$ \\
\hline South Medical University & $21.8(398)$ & $23.0(132)$ & $21.2(266)$ \\
\hline Shaanxi University Chinese Medicine & $21.6(396)$ & $17.5(100)$ & $23.5(296)$ \\
\hline \multicolumn{4}{|l|}{ Well-being } \\
\hline Social network, mean (SD) & $14.9(5.3)$ & $15.7(6.0)$ & $14.6(4.9)^{* * *}$ \\
\hline Satisfaction of life, mean (SD) & $19.2(5.9)$ & $18.9(5.9)$ & $19.3(5.9)$ \\
\hline Purpose of life, mean (SD) & $19.7(4.3)$ & $19.8(4.7)$ & $19.6(4.1)$ \\
\hline Quality of life, mean (SD) & $80.7(12.5)$ & $81.3(12.2)$ & $80.5(12.7)$ \\
\hline \multicolumn{4}{|l|}{ Religious involvement } \\
\hline RCI total score, mean (SD) & $23.4(9.1)$ & $23.9(9.5)$ & $23.1(8.9)$ \\
\hline Intrapersonal religious, mean (SD) & $13.5(5.9)$ & $13.8(6.2)$ & $13.3(5.8)$ \\
\hline Interpersonal religious, mean (SD) & $9.9(3.5)$ & $10.1(3.7)$ & $9.8(3.5)$ \\
\hline \multicolumn{4}{|l|}{ Religious affiliation } \\
\hline Buddhist/Taoist, \% (n) & $13.8(252)$ & $16.0(92)$ & $12.7(160)$ \\
\hline Muslim, \% (n) & $18.0(329)$ & $19.4(111)$ & $17.3(218)$ \\
\hline Christian/Catholic, \% (n) & $1.6(30)$ & $1.6(9)$ & $1.7(21)$ \\
\hline No affiliation, \% (n) & $66.6(1,219)$ & $63.0(361)$ & $68.3(858)$ \\
\hline
\end{tabular}

\# Comparison for male vs. female

$* \mathrm{p}<0.05, * * * \mathrm{p}<0.001$

\subsection{Research Design}

The survey was conducted during a three week period from April $28^{\text {th }}$ to May 16 ${ }^{\text {th }}$, 2014. Questionnaires were administered to students in classrooms at the university and were collected at that time. The same survey was then re-administered two weeks later to a subsample of 152 students to determine test-retest reliability, 133 of whom completed the survey a second time.

The survey design was anonymous and no identifying information was included on the questionnaire. Informed consent was the first section of the questionnaire that described the study and its voluntary nature, and all participants were required to give their consent before beginning the questionnaire. The study was approved by the Institutional Review Board of the Ningxia Medical University (No. 2014-171).

\subsection{Measures}

The questionnaire included a Chinese version of the BIAC scale, Religious Commitment Inventory (RCI-10), the Purpose in Life (PIL) scale, and the Social Integration Scale (SIS), along with a battery of Chinese mental health scales and demographic questions, including age, gender, parents' highest level of education, residence (rural vs. urban), ethnicity (Han vs. minority ethnicity), and religious affiliation. 


\subsubsection{Religious Characteristics}

Religious affiliation was determined by asking, "What is your religious preference?" Religious affiliation was coded for analyses into four categories: $1=$ Chinese religion (i.e., Buddhist, Taoist, etc.), $2=$ Muslim, $3=$ Western religion (i.e., Christian, Catholic, etc.), and 4= none. Religiosity was measured use the BIAC scale and RCI-10.

The BIAC scale consists of 10 items (Koenig et al., 2015). Nine of the 10 items are rated on a Likert-type scale from 1 to 10; one item (\#1) is scored 10 if the respondent indicates "relationship with Buddha, Allah or God" as his or her highest priority in life, whereas all other responses receive a score of 1 . The total score ranges from 10 to 100 , with higher scores indicating greater religiosity. In the original validation study involving 251 adult females (87\% Christian) from the East and West coasts of the U.S., the average score was 46.3 (range 10-90); Cronbach alpha was 0.89; and the intra-class correlation coefficient between two administrations $(n=60)$ was 0.92 . Convergent validity was demonstrated by high correlations between the BIAC and existing religiosity scales; divergent validity by weak correlations with mental, social, and physical health outcomes; and construct validity by high correlations between individual items and total scale score (r's $0.58-0.80$ ). A single factor in that study explained $94.4 \%$ of the scale's variance.

The RCI-10 is a brief 10-item measure of religious commitment (Worthington et al., 2003). Responses are rated on a 5-point Likert rating scale from 1 ("not at all true of me") to 5 ("totally true of me"). The RCI-10 measures the extent to which an individual adheres to his or her religious beliefs, values, and practices and whether he/she utilizes them in everyday life. RCI-10 has two subscales that assess intrapersonal religious commitment (6 items) and interpersonal commitment (4 items). Higher scores indicate higher religiosity.

The original English versions of the BIAC scale and RCI-10 were translated into Chinese by two bilingual Chinese scholars. The translations were compared and discrepancies reconciled to arrive at a common Chinese version. The Chinese version was back-translated into English independently by two bilingual Chinese-English scholars, one at the Institute of Brain and Mind at the University of Sydney, Australia and another at the Duke University Chapel, Durham, North Carolina, USA. The back-translated English version was then compared to the original English version to determine whether the questions were properly translated, and discrepancies were resolved. After examining the back translations and feedback from these two Chinese-English scholars, the Chinese versions of the BIAC and RCI-10 scales were piloted in 10 university students at Ningxia Medical University to assess their appropriateness and readability. After taking into consideration the students' feedback, the language was further clarified and the final Chinese versions of the scales were arrived at.

\subsubsection{Social Network}

The 4-item social interaction subscale of Duke Social Support Index (DSSI) (Koenig, Westlund, George, Hughes, Blazer, Hybels, 1993) was used to measure social support, where higher scores indicate greater social interaction. The DSSI has been used in China for studying the relationships between social support and mental health in younger adults, and has solid psychometric properties in this population (alpha=0.76) (Zhang, 2012).

\subsubsection{Satisfaction of life}

The Satisfaction With Life Scale (SWLS) (Diener , 1985) was used to assess global life satisfaction. The SWLS was developed by Diener and has been widely used in studies of life satisfaction. A Chinese version of the SWLS was developed by Xing at 2002, and was found to be reliable, valid, and acceptable to Chinese citizens (Xing, 2002).

\subsubsection{Purpose of Life}

The Purpose in Life Test-Short Form (PLT-SF) (Schulenberg, 2011)was used to measure the extent to which participants felt that their lives had meaning and life purpose. The PLT-SF was originally found to have solid psychometric properties and was predictive of psychological distress. A Chinese version of the PLT-SF has likewise been shown to have high reliability (alpha=0.89) and good construction validity (Law, 2012).

\subsubsection{Quality of Life}

A visual analog scale (VAS) from the EuroQol (EQ-5D) (EuroQol, 1990) was used to measure health-related quality of life. The VAS is rated on an interval scale like a "ruler" with a range from 0 (worst health imaginable) to 100 (best imaginable health). Participants are asked to mark a cross on the line showing the point on the thermometer that reflects the quality of their health on that day. The EQ-5D has been widely used in assessing health related quality of life in Chinese populations (Lee, 2013).

\subsection{Statistical Analyses}

The data were double-entered into EpiData 3.1. Missing values were replaced by the total sample median value for those responding to $70 \%$ or more of the entire questionnaire. If more than $30 \%$ of items on the questionnaire were missing, the participant was excluded from analyses. Descriptive analyses were performed on all subjects depending on 
whether responses were categorical or continuous. Differences in socio-demographic characteristics between male and female participants were compared using the Student's t-test for continuous variables and the chi-square test for categorical variables. Difference on BIAC scale scores between males and females were examined using one-way analysis of variance (ANOVA), and eta-squared ( $\eta 2)$ was used to measure the effect size. The normality of the BIAC scale item scores and total score were examined using the Kolmogorov-Smirnov test, and logarithmic transformation of the data was performed to normalize the scores. Convergent/divergent validity was evaluated by examining the correlations between BIAC scale and other measures. The Pearson correlation was used to create the correlation matrix.

Internal reliability and test-retest reliability were performed for the total sample and for male and female participants, respectively. The Cronbach's alpha coefficient (Bland \& Altman, 1997) was used to assess internal consistency of the total BIAC scale; alpha coefficients greater than 0.70 are considered acceptable. In addition, the alpha of the scale was determined if each of the items were deleted, showing the importance of the item to the scale's overall reliability. The intra-class correlation coefficient (ICC) was used to measure the scale's test-retest reliability, where ICCs between 0.41 and 0.60 indicate moderate reliability, those between 0.61 and 0.80 represent good reliability, and those higher than 0.80 indicate excellent reliability (Bartko, 1966).

Exploratory factor analysis (EFA) and confirmatory factor analysis (CFA) were conducted to extract the scale factors. The sample was divided into two groups using computer-generated random numbers. EFA was performed on the first group ( $\mathrm{n}=915)$ using principal components analysis with Promax rotation (an oblique rotation method that allows factors to correlate with each other). Kaiser-Meyer-Olkin (KMO) index was used to measure sample adequacy, where $\mathrm{KMO}$ values of 0.6 or higher indicate sampling adequacy. The Bartlett's test of sphericity was used to assess the appropriateness of the correlations among variables for the factor model. A value with $p<0.05$ in Bartlett's test of sphericity suggests that the data are factorable.

CFA using the maximum likelihood method was performed in the second group ( $\mathrm{n}=915)$ to assess stability of the factor structure identified in the first group. Values for the model, indices for model fit, modification indices (MI), and standardized estimations were computed. Model adequacy was determined using the chi-square test with degrees of freedom (df). If the $\mathrm{p}$ value is $<0.05$, the model is considered acceptable and should improve with smaller $\chi^{2}$ values and larger df. Indices for the model fit included the comparative fit index (CFI), normed fit index (NFI), incremental fit index (IFI) and root mean square error of approximation (RMSEA); information-theoretic measures included the Akaike information criterion (AIC), and a constant scale factor (EVCI). Values of CFI > 0.90, NFI >0.90, IFI > 0.90, and RMSEA $<0.08$ indicate that the model fit is acceptable. The smaller values of AIC, BCC and EVCI indicate better model fit. Standardized estimation was used in building model paths. All the statistical analyses were completed using SPSS 16.0 software (SPSS Inc., Chicago, IL, USA).

\section{Results}

\subsection{BIAC Item Scores}

The BIAC scale individual item and summary scores are presented in Table 2. Again, somewhat surprisingly, women scored lower than men on the total score (14.9 vs. 17.2, $\mathrm{p}<0.001)$.

Table 2. Individual and total item scores for Belief into Action (BIAC) scale

\begin{tabular}{lcccc}
\hline & $\begin{array}{c}\text { Overall } \\
(\mathrm{n}=1,830) \\
\text { Mean }(S D)\end{array}$ & $\begin{array}{c}\text { Male } \\
(\mathrm{n}=573) \\
\text { Mean }(S D)\end{array}$ & $\begin{array}{c}\text { Female }^{\#} \\
(\mathrm{n}=1,257)\end{array}$ & $\eta^{2}$ \\
\hline Bean $($ SD) & \\
BIAC1 (God highest priority) & $1.25(1.49)$ & $1.42(1.90)$ & $1.17(1.25)^{* * *}$ & .005 \\
BIAC 3 (other religious meetings) & $1.82(1.31)$ & $2.16(1.71)$ & $1.67(1.05)^{* * *}$ & .030 \\
BIAC 4 (extent life under God) & $1.56(1.10)$ & $1.75(1.42)$ & $1.48(0.90)^{* * *}$ & .013 \\
BIAC 5 (percent annual income) & $2.16(2.02)$ & $2.13(2.09)$ & $2.17(1.99)$ & .000 \\
BIAC 6 (time on religious media) & $2.06(2.00)$ & $2.15(2.16)$ & $2.02(1.92)$ & .001 \\
BIAC 7 (time reading scriptures) & $1.63(1.23)$ & $1.74(1.42)$ & $1.58(1.12)^{*}$ & .003 \\
BIAC 8 (time prayer/meditation) & $1.35(1.03)$ & $1.48(1.22)$ & $1.29(0.92)^{* *}$ & .007 \\
BIAC 9 (time volunteering for religious) & $1.52(1.33)$ & $1.62(1.46)$ & $1.48(1.26)$ & .007 \\
BIAC 10 (conform life to religion) & $1.24(0.83)$ & $1.32(1.04)$ & $1.20(0.71)^{*}$ & .007 \\
Total Score & $15.26(0.88)$ & $1.37(1.15)$ & $1.21(0.72)^{* *}$ & .006 \\
\hline
\end{tabular}

\# Comparison of male vs. female; $*<0.05, * * \mathrm{p}<0.01, * * * \mathrm{p}<0.001 ;$ Response options for all items are on a 1-10 Likert-type scale, except BIAc1 (where 10=God as highest priority in life vs. 1=all other priorities) 


\subsection{Convergent/Discriminant Validity}

Bivariate correlations among BIAC total score, RCI-10 subscales score, religious affiliation and mental and social health variables were examined to assess construct validity (Table 3 ). The BIAC total score and the RCI-10 subscale scores were strongly and positively correlated $(r=0.67$ and $0.60, p<0.001)$, indicating good convergent validity. The same was true for religious affiliation $(r=0.56, p<0.001)$. The BIAC scale score was more weakly associated with social interaction $(\mathrm{r}=0.10)$, with life satisfaction $(\mathrm{r}=0.02)$, purpose in life $(\mathrm{r}=0.01)$, and quality of life $(-0.02)$, indicating good divergent validity.

Table 3. Correlation matrix

\begin{tabular}{|c|c|c|c|c|c|c|c|c|c|c|}
\hline Variable & 1 & 2 & 3 & 4 & 5 & 6 & 7 & 8 & 9 & 10 \\
\hline 1.Gender & 1.00 & & & & & & & & & \\
\hline 2. Education of parents & $0.06^{*}$ & 1.00 & & & & & & & & \\
\hline 3.Religious affiliation ${ }^{\#}$ & $-0.05^{*}$ & $-0.21^{* * *}$ & 1.00 & & & & & & & \\
\hline 4.BIAC scale & $-0.09^{* *}$ & $-0.16^{* *}$ & $0.56^{* * *}$ & 1.00 & & & & & & \\
\hline 5.RCI-10 intrapersonal & -0.03 & $-0.17^{* *}$ & $0.54^{* * *}$ & $0.67^{* * *}$ & 1.00 & & & & & \\
\hline 6.RCI-10 interpersonal & -0.04 & $-0.17^{* *}$ & $0.50^{* * *}$ & $0.60^{* * *}$ & $0.82^{* *}$ & 1.00 & & & & \\
\hline 7. Social interaction & $-0.09^{* *}$ & 0.00 & $0.09^{* *}$ & $0.10^{* *}$ & $0.07^{* *}$ & $0.07^{* *}$ & 1.00 & & & \\
\hline 8. Life satisfaction & 0.03 & $0.11^{*}$ & -0.04 & 0.02 & 0.03 & $0.06^{*}$ & $0.15^{* * *}$ & 1.00 & & \\
\hline 9. Purpose in life & -0.01 & 0.05 & -0.01 & 0.01 & 0.03 & $0.05^{*}$ & $0.22^{* * *}$ & $0.37^{* * * *}$ & 1.00 & \\
\hline 10. Quality of life & -0.03 & 0.01 & 0.01 & -0.02 & -0.04 & -0.00 & $0.20^{* *}$ & $0.24^{* * *}$ & $0.36^{* * *}$ & 1.00 \\
\hline
\end{tabular}

\# Recoded into with religion affiliation vs. without religion affiliation

BIAC $=$ Beliefs into Action Scale, RCI-10=Religious Commitment Scale-10

$*<0.05, * * \mathrm{p}<0.01, * * * \mathrm{p}<0.001$ (two-tailed)

\subsection{Internal Reliability}

As shown in Table 4, the reliability coefficients if the item was deleted (Cronbach's $\alpha$ ) for individual items on the BIAC scale in the total sample ranged from 0.80 to 0.84 , from 0.83 to 0.87 in male, and from 0.78 to 0.83 in female, respectively. The Cronbach's $\alpha$ for the total score was 0.83 in all subjects, 0.86 in females, and 0.81 in males.

Table 4. Cronbach's alpha for scale with individual items deleted and for total score

\begin{tabular}{clll}
\hline Items & $\begin{array}{l}\text { Overall } \\
(\mathrm{n}=1,830)\end{array}$ & $\begin{array}{l}\text { Male } \\
(\mathrm{n}=573)\end{array}$ & $\begin{array}{l}\text { Female } \\
(\mathrm{n}=1257)\end{array}$ \\
\hline BIAC1 & .84 & .87 & .83 \\
BIAC 2 & .80 & .83 & .78 \\
BIAC 3 & .81 & .84 & .79 \\
BIAC 4 & .81 & .84 & .78 \\
BIAC 5 & .80 & .83 & .78 \\
BIAC 6 & .81 & .84 & .80 \\
BIAC 7 & .82 & .84 & .80 \\
BIAC 8 & .83 & .85 & .81 \\
BIAC 9 & .82 & .84 & .79 \\
BIAC10 & .82 & .84 & .80 \\
Total Score & .83 & .86 & .81 \\
\hline
\end{tabular}

* Alpha for the individual items refers to alpha for scale if item deleted 


\subsection{Test-Retest Reliability.}

ICC's for the individual BIAC scale items ranged from 0.41 to 0.90 , and the ICC for the total score was 0.86 (Table 5). With regard to gender, the ICC of the total score in men was 0.86 and for individual items ranged from 0.36 to 0.91 , except for BIAC7 where a negative variance due to the nature of the algorithms used constrained the ICC to zero. Among women, the ICC for the total score was 0.86 and the ICC for individual items ranged from 0.30 to 0.95 .

Table 5. Test-retest reliability of Belief into Action (BIAC) scale

\begin{tabular}{cccccc}
\hline Items & $\begin{array}{c}\text { Time 1 } \\
\text { Mean }(S D)\end{array}$ & $\begin{array}{c}\text { Time 2 } \\
\text { Mean }(S D)\end{array}$ & $\begin{array}{c}\text { Overall } \\
(\mathrm{n}=133) \\
\text { ICC }\end{array}$ & $\begin{array}{c}\text { Male } \\
(\mathrm{n}=47) \\
\text { ICC }\end{array}$ & $\begin{array}{c}\text { Female } \\
(\mathrm{n}=86) \\
\text { ICC }\end{array}$ \\
\hline BIAC1 & $1.20(1.34)$ & $1.07(0.78)$ & .45 & .53 & .40 \\
BIAC2 & $1.93(1.47)$ & $1.71(1.21)$ & .90 & .91 & .84 \\
BIAC3 & $1.64(1.22)$ & $1.50(1.00)$ & .81 & .82 & .78 \\
BIAC4 & $2.02(1.97)$ & $1.90(1.89)$ & .76 & .83 & .63 \\
BIAC5 & $2.02(2.15)$ & $1.97(2.01)$ & .79 & .82 & .76 \\
BIAC6 & $1.69(1.45)$ & $1.55(1.27)$ & .66 & .86 & .30 \\
BIAC7 & $1.18(0.59)$ & $1.30(1.07)$ & .66 & .00 & .95 \\
BIAC8 & $1.38(1.11)$ & $1.32(1.12)$ & .41 & .36 & .42 \\
BIAC9 & $1.19(0.68)$ & $1.22(0.99)$ & .65 & .73 & .64 \\
BIAC10 & $1.20(0.80)$ & $1.22(0.94)$ & .36 & .42 & .28 \\
Total Score & $15.5(9.3)$ & $14.8(8.9)$ & .86 & .86 & .86 \\
\hline
\end{tabular}

ICC: Intra-class Correlation Coefficient

\subsection{Principle Factor Analysis}

For the EFA in the first group, the overall KMO index was 0.83, and KMS values for individual items ranged from 0.77 to 0.92 , where values greater than 0.60 indicate sample adequacy. The Bartlett's test of sphericity indicated that the sample was factorable at $\mathrm{p}<0.001\left(X^{2}{ }_{10}=3.80 \mathrm{E}^{3}\right)$. EFA with an oblique rotation was performed to examine the dimensions of the BIAC scale. As shown in Table 6, two factors were extracted that explained $57.5 \%$ of total variance. In this two factor model, BIAC1 had a factor loading of 0.43 on factor 1 and 0.13 on factor 2 . A three factor model revealed better structure than the two factor model, with the former explaining $66.3 \%$ of the total variance. As illustrated in Table 6, factor 1 ("social") included items BIAC2, BIAC3, BIAC4, and BIAC5, and based on the content of the items, appeared to measure religious activities that were more social in nature, whereas factor 2 ("personal") included items BIAC6, BIAC7, BIAC8, BIAC9, and BIAC10, which appeared to measure religious activities that were indicative of personal religiosity. Factor 3 ("God factor) was made up of only one item BIAC1, which measures the overall priority that respondents placed on their relationship with God relative to other priorities in their lives. Because of the importance of BIAC1 and the increase in overall variance explained by the BIAC scale that included it, this item was not discarded (as might ordinarily be done) but was included as a separate factor.

\subsection{Confirmatory Factor Analysis}

In the other half of the sample, CFA verified the three factor model for the BIAC scale $\left(\chi^{2}=232.03 ; \mathrm{df}=31 ; p<0.001\right.$, $\mathrm{CFI}=.95, \mathrm{NFI}=0.94, \mathrm{IFI}=.95, \mathrm{RMSEA}=.084, \mathrm{AIC}=280.3$, and $\mathrm{EVCI}=.30)($ see Figure 2$)$.

\section{Discussion}

We examined the psychometric properties of a Chinese version of the BIAC scale in college students selected from three different provinces of Mainland China. The results indicated that this scale has solid internal consistency and test-retest reliability as a measure of religiosity in Chinese young adults. The item distributions across men and women indicated adequate distributions of response in a population with low religiosity. Interestingly, men scored higher on religiosity using the BIAC scale than did women, which is the opposite of what is usually found in western countries (Francis, 1997; Levin, Taylor, \& Chatters, 1994). Given the size of the sample, significant differences between genders are not particularly surprising (and effect size is tiny, 0.00-0.03); however, even if religiosity was similar between young men and women in China, it would still contrast with findings in the West that almost uniformly report that women are more religious than men. This confirms results from another study that examined religiosity among Chinese college students using the Duke University Religion Index (DUREL) (Wang, Rong, \& Koenig, 2014).

Convergent validity was also demonstrated by the strong correlations between total BIAC score and RCI-10 subscale scores, and the same was true for the difference in BIAC score between those with and without a religion affiliation. The inverse association between religiosity and family income is also in line with previous reports (Neberich., 2013). 
Table 6. Comparison of the two factor structure model of the BIAC scale $(n=915)$

\begin{tabular}{|c|c|c|c|c|c|}
\hline \multirow{3}{*}{ Items } & \multicolumn{2}{|c|}{ Two factor model } & \multicolumn{3}{|c|}{ Three factor model } \\
\hline & \multicolumn{2}{|c|}{ Component } & \multirow[b]{2}{*}{1} & \multirow[b]{2}{*}{2} & \multirow[b]{2}{*}{3} \\
\hline & 1 & 2 & & & \\
\hline BIAC1 & .43 & .13 & .27 & .15 & .89 \\
\hline BIAC2 & .82 & .47 & .85 & .41 & .07 \\
\hline BIAC3 & .74 & .47 & .78 & .42 & -.01 \\
\hline BIAC4 & .81 & .31 & .77 & .27 & .41 \\
\hline BIAC5 & .85 & .33 & .83 & .28 & .32 \\
\hline BIAC6 & .55 & .63 & .59 & .60 & -.01 \\
\hline BIAC7 & .32 & .79 & .32 & .80 & .09 \\
\hline BIAC8 & .19 & .66 & .17 & .68 & .18 \\
\hline BIAC9 & .43 & .83 & .46 & .83 & .01 \\
\hline BIAC10 & .40 & .77 & .45 & .76 & -.11 \\
\hline
\end{tabular}

Factor loading for the structure matrix listed above

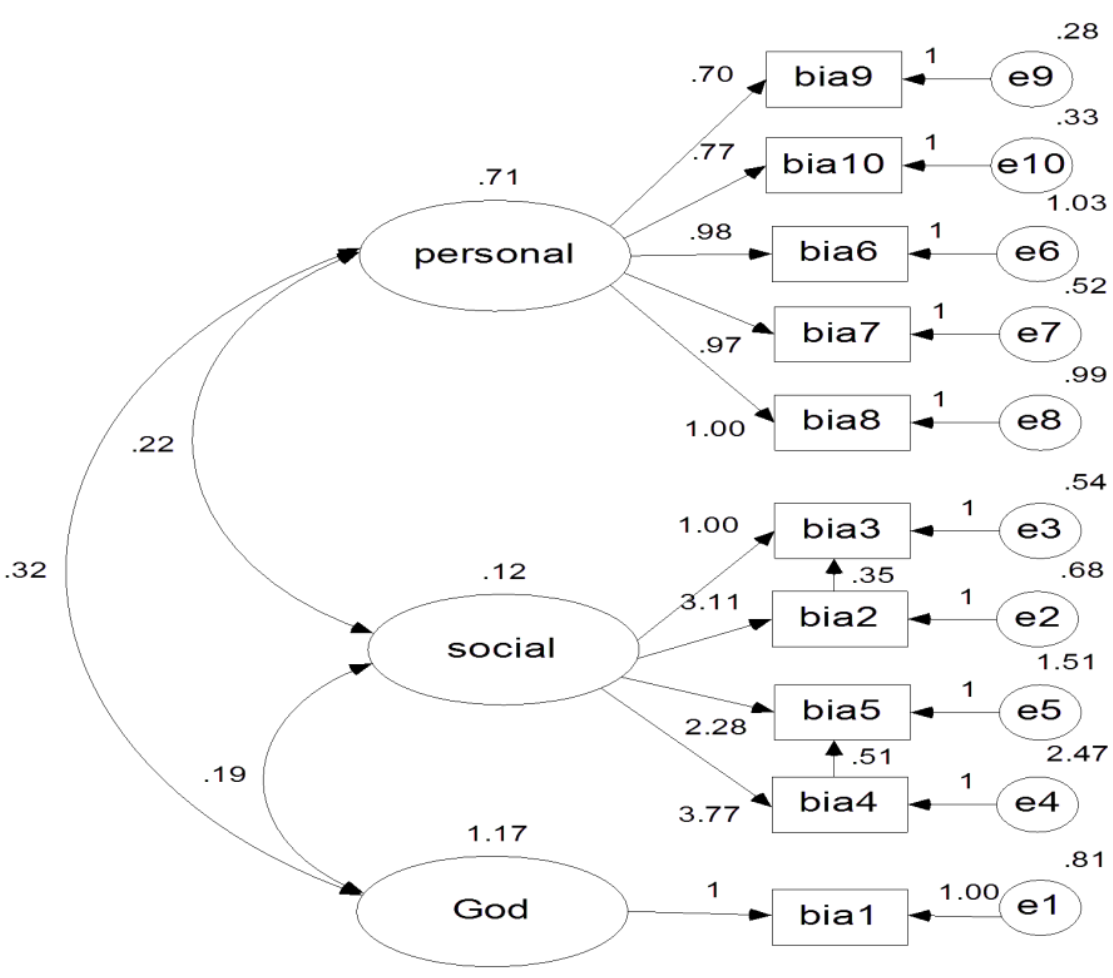

Figure 2. The confirmatory factor analysis model $(n=915)$ 
Convergent validity was also demonstrated by the strong correlations between total BIAC score and RCI-10 subscale scores, and the same was true for the difference in BIAC score between those with and without a religion affiliation. The inverse association between religiosity and family income is also in line with previous reports (Neberich., 2013). Evidence for divergent validity was observed based on the weak correlations between the BIAC total score and social support, satisfaction in life, purpose in life, and health-related quality of life, all of which were low $(\mathrm{r}<0.11)$. This suggests that the BIAC scale is capable of discriminating between religiosity and similar constructs related to mental and social health. The strongest correlation was found with social interaction, which is consistent with what others have found with regard to religiosity (Koenig et al., 1997; Krause, Ingersoll-Dayton, Liang, \& Sugisawa, 1999; Moxey, McEvoy, Bowe, \& Attia, 2011).

Test-retest reliability ICCs for the BIAC scale were also acceptable for the total scale, despite the low ICC for BIAC7 in males and BIAC8 and BIAC10 overall. There are several possible explanations for the low ICCs for some items, given that the sample was made up of a mixture of Buddhist, Muslim and atheistic religions across China, as well as traditional Chinese religions where the frequency of private religious activities are difficult to distinguish from traditional life activities in general (Fowler \& Fowler, 2008). Consequently, participants are less likely to be able to provide accurate and stable responses. In addition, Chinese college students are often discouraged from engaging in religious activities by university administrators. It may also have been difficult for participants to recall the frequency of personal religious activities such as time spent on reading religious scripture or in prayer, given the overall low frequency of these activities.

The findings here also supported the theoretical grounds on which the BIAC scale was constructed, and the actual content of the items that made up the scale. The EFA revealed two factors which reflected personal religious activities and social religious activities, two of the three major dimensions of religiosity based on a National Institute on Aging-Fetzer Institute Consensus conference held almost two decades ago (Koenig \& Futterman, 1995). However, we had two concerns about the two-factor model. First, is that the total variance explained was less than $60 \%$, suggesting that too much information was lost with this two-factor model. Second, the factor loading of item 1 was less than 0.5 for both factor 1 and factor 2, which provides little justification for including this item on either of these factors. Some experts insist that researchers should examine the content of scale items and then decide whether the factors make sense (i.e., that items cohere). As a result, this is the criterion that many now use, in addition to eigenvalue, scree plot test, and total variance. To overcome these weaknesses of the two factor model, we identified a three factor model based on the scale content, and given the three major dimensions of religiosity noted above, that included a cognitive dimension related to the importance of religion as a priority in life. Considering the content of the BIAC1 (i.e., "Which of the following do you consider as "most important"?, followed by a list of common priorities in life, including "my relationship with Buddha, Allah or God"), this item really deserves its own factor and fits very nicely in representing the third dimension of religiosity missing in factors 1 and 2. Furthermore, the confirmatory factor analysis supported the 3 -factor model suggesting that there were three distinct dimensions to the BIAC scale.

\subsection{Limitations}

First, a high proportion of participants in this study had no religious affiliation, making it difficult to compare the findings to previous studies from Western countries. Second, cultural differences between China and the West (where the BIAC scale was original developed and designed for use) may have affected the translation of the BIAC scale here (both the translation and the meaning of items). Third, the present study was conducted in a college student sample, which may not be generalizable to community samples in China, requiring that future studies evaluate the psychometric properties of the BIAC scale in general community populations.

\subsection{Conclusions}

The present study conducted largely among non-Christian college students found that the BIAC scale is a reliable and valid measure of religiosity in this Mandarin-speaking sample, providing cross-cultural evidence that the BIAC scale can be used to assess religiosity in Mainland China, a region of the world with a high proportion of persons who are not religious.

\section{References}

Bartko, J. J. (1966). The intraclass correlation coefficient as a measure of reliability. Psychological Reports, 19(1), 3.

Bland, J. M., \& Altman, D. G. (1997). Cronbach's alpha. British Medical Journal, 314(7080), 572-572.

Bonelli, R. M., \& Koenig, H. G. (2013). Mental disorders, religion and spirituality 1990 to 2010: a systematic evidence-based review. Journal of Religion and Health, 52(2), 657-673. http://dx.doi.org/10.1007/s10943-013-9691-4

Chuah, O. (2004). Muslims in China: the social and economic situation of the Hui Chinese. Journal of Muslim Minority 
Affairs, 24(1), 155-162. http://dx.doi.org/ 10.1080/1360200042000212133

Diener, E, E. R., \& Larsen, R. J. (1985). The satisfaction with life scale. Journal of Personality, 49(1), 71-75.

EuroQol, G. (1990). EuroQol - a new facility for the measurement of health-related quality of life. Health Policy, 16(3), 199-208. http://dx.doi.org/ 10.1016/0168-8510(90)90421-9

Fan, L. (2003). Popular religion in contemporary China. Social Compass, 50, 449-457. http://dx.doi.org/ 10.1177/ 0037768603504004

Fowler, J. D., \& Fowler, M. (2008). Chinese religions: beliefs and practices. Brighton: Sussex Academic Press.

Francis, L. J. (1997). The Psychology of Gender Differences in Religion: A Review of Empirical Research. Religions, 27(1), 81-96. http://dx.doi.org/ 10.1006/reli.1996.0066

Hill, P. C., \& Hood Jr., R. W. (1999). Measures of Religiosity. Birmingham, AL: Religious Education Press.

King, M., Speck, P., \& Thomas, A. (2001). The royal free interview for spiritual and religious beliefs: development and validation of a self-report version. Psychological Medicine, 31(6), 1015-1023. http://dx.doi.org/ $10.1017 /$ S0033291701004160

Koenig, H. G. (2008). Concerns About Measuring "Spirituality" in Research. The Journal of Nervous and Mental Disease, 196(5), 349-355. http://dx.doi.org/ 10.1097/NMD.0b013e31816ff796

Koenig, H. G. (2012). Religion, spirituality, and health: the research and clinical implications. ISRN Psychiatry, 2012, 278730. http://dx.doi.org/ 10.5402/2012/278730

Koenig, H. G., Nelson, B., Shaw, S. F., Al Zaben, F., Wang, Z., \& Saxena, S. (2015). Belief into Action scale: A brief but comprehensive measure of religious commitment. Open Journal of Psychiatry. 5(1), 66-77. http://dx.doi.org/ 10.4236/ojpsych.2015.51010

Koenig, H. G., \& Futterman, A. (1995). Religion and health outcomes: A review and synthesis of the literature. Methodological Approaches to the Study of Religion, Aging, and Health, National Institute on Aging, Bethesda, MD, March, 16-17.

Koenig, H. G., Hays, J. C., George, L. K., Blazer, D. G., Larson, D. B., \& Landerman, L. R. (1997). Modeling the cross-sectional relationships between religion, physical health, social support, and depressive symptoms. American Journal of Geriatric Psychiatry, 5(2), 131-144.

Koenig, H. G., Westlund, R. E., George, L. K., Hughes, D. C., Blazer, D. G., \& Hybels, C. (1993). Abbreviating the Duke Social Support Index for use in chronically ill elderly individuals. Psychosomatics, 34, 61-69.

Krause, N., Ingersoll-Dayton, B., Liang, J., \& Sugisawa, H. (1999). Religion, social support, and health among the Japanese elderly. Journal of Health \& Social Behavior, 40(4), 405-421.

Krauss, S. E., Hamzah, A., \& Idris, F. (2007). Adaptation of a Muslim Religiosity Scale for Use with Four Different Faith Communities in Malaysia. Review of Religious Research, 49(2), 147-164.

Law, B. M. F. (2012). Psychometric Properties of the Existence Subscale of the Purpose in Life Questionnaire for Chinese Adolescents in Hong Kong. The Scientific World Journal, 2012. http://dx.doi.org/ 10.1100/2012/685741

Lee, C. F., Wong, C., Goh, C., Cheung, Y. B., Ng, R., Luo, N., \& Krishna, L. (2013). The English and Chinese versions of the five-level EuroQoL Group's five-dimension questionnaire (EQ-5D) were valid and reliable and provided comparable scores in Asian breast cancer patients. Supportive Care in Cancer, 21(1), 201-209. http://dx.doi.org/ $10.1007 / \mathrm{s} 00520-012-1512-\mathrm{x}$

Levin, J. S., Taylor, R. J., \& Chatters, L. M. (1994). Race and Gender Differences in Religiosity Among Older Adults: Findings From Four National Surveys. Journal of Gerontology, 49(3), S137-S145. http://dx.doi.org/ 10.1093/geronj/49.3.S137

Moxey, A., McEvoy, M., Bowe, S., \& Attia, J. (2011). Spirituality, religion, social support and health among older Australian adults. Australasian Journal on Ageing, 30(2), 82-88. http://dx.doi.org/ 10.1111/j.1741-6612.2010.00453.x

Neberich., J. E. G. A. D. N. C. S. W. (2013). The Psychological Benefits of Income are Contingent on Individual-Level and Culture-Level Religiosity. Social Psychological and Personality Science, 4(5), 569-578. http://dx.doi.org/ $10.1177 / 1948550612469819$

Sampford, M. R. (1962). Methods of Cluster Sampling With and Without Replacement for Clusters of Unequal Sizes. Biometrika, 49(1/2), 27-40. http://dx.doi.org/ 10.1093/biomet/49.1-2.27 
Schulenberg, S. E., Schnetzer L. W., \& Buchanan, E. M. ( 2011). The Purpose in Life Test-Short Form: Development and Psychometric Support. Journal of Happiness Studies, 12(5), 861-876.

Stark, R., \& Liu, E.Y. (2011). The religious awakening in China. Review of Religious Research, 52, 282-289.

Traphagan, J. W. (2005). Multidimensional Measurement of Religiousness/Spirituality for Use in Health Research in Cross-Cultural Perspective. Research on Aging, 27(4), 387-419. http://dx.doi.org/ 10.1177/0164027505276049

Wang Z., Rong Y., \& Koenig H. G. (2014). Psychometric Properties of a Chinese Version of the Duke University Religion Index in College Students and Community Residents in China. Psychological Reports, 115(2), 427-443. http://dx.doi.org/ 10.2466/08.17

Worthington, E. L., Wade, N.G., Ripley, J. S., Hight, T. L., McCullough, M. E., Berry, J. T., Berry, J. W., Schmitt, M. M., Bursley, K. H., \& O'Connor, L. (2003). The Religious Commitment Inventory-10: Development, refinement, and validation of a brief scale for research and counseling. Journal of Counseling Psychology, 50(1), 84-96, http://dx.doi.org/ 10.1037/0022-0167.50.1.84

Xing, Z. J., Wang, X. Z., \& Jiao, L. P. (2002). Report on Several Familiar Self-reported Subjective Well-being Scales Applied to Citizens in China. Journal of Healthy Psychology, 5, 325-326.

Yang, F. G. (2010). Religion in China under Communism: A Shortage Economy Explanation. Journal of Church and State, 52(1), 3-33. http://dx.doi.org/ 10.1093/jcs/csp042

Zhang J., \& Jia, C. X. (2012). Psychometric Characteristics of the Duke Social Support Index in a Young Rural Chinese Population. Death Studies, 36(9), 858-869. http://dx.doi.org/ 10.1080/07481187.2011.604462

\section{(cc) BY}

This work is licensed under a Creative Commons Attribution 3.0 License. 